\title{
Intra-tumor heterogeneity: lessons from microbial evolution and clinical implications
}

\author{
Elza C de Bruin ${ }^{1 \dagger}$, Tiffany B Taylor ${ }^{2^{* \dagger}}$ and Charles Swanton ${ }^{1,3^{*}}$
}

\begin{abstract}
Multiple subclonal populations of tumor cells can coexist within the same tumor. This intra-tumor heterogeneity will have clinical implications and it is therefore important to identify factors that drive or suppress such heterogeneous tumor progression. Evolutionary biology can provide important insights into this process. In particular, experimental evolution studies of microbial populations, which exist as clonal populations that can diversify into multiple subclones, have revealed important evolutionary processes driving heterogeneity within a population. There are transferrable lessons that can be learnt from these studies that will help us to understand the process of intra-tumor heterogeneity in the clinical setting. In this review, we summarize drivers of microbial diversity that have been identified, such as mutation rate and environmental influences, and discuss how knowledge gained from microbial experimental evolution studies may guide us to identify and understand important selective factors that promote intra-tumor heterogeneity. Furthermore, we discuss how these factors could be used to direct and optimize research efforts to improve patient care, focusing on therapeutic resistance. Finally, we emphasize the need for longitudinal studies to address the impact of these potential tumor heterogeneity-promoting factors on drug resistance, metastatic potential and clinical outcome.
\end{abstract}

\section{Patterns of tumor evolution}

In 1976, Peter Nowell published a landmark paper [1] in which he applied the evolutionary biology concept of 'survival of the fittest' to the field of tumor progression; he proposed that tumor cells will undergo changes (acquire mutations), and selection pressures will facilitate the outgrowth of some clones but not others. This concept of clonal evolution has been developed further into two models: linear versus branched tumor evolution (Figure 1). The linear model states that tumor cells acquire mutations over time, and that the fittest tumor cells outgrow the other cells through clonal succession, implying that the majority of the tumor mass will consist of the fittest clone [2,3]. Another important characteristic of this model is that the fittest clone will harbor all mutations that have previously occurred during the tumor's evolutionary history (Figure 1a). The branched

\footnotetext{
* Correspondence: T.B.Taylor@reading.ac.uk; Charles.Swanton@cancer.org.uk ${ }^{\dagger}$ Equal contributors

${ }^{2}$ School of Biological Sciences, University of Reading, Whiteknights, Reading, Berkshire RG6 6AH, UK

'Translational Cancer Therapeutics Lab, UCL Cancer Institute, University College London, London WC1E 6DD, UK

Full list of author information is available at the end of the article
}

tumor evolution model states that different tumor cells acquire different mutations over time, and that multiple clones can expand independently within the tumor (Figure 1b) $[2,3]$. However, it is important to note that finding a tumor mass that contains one clone does not necessarily mean that branched evolution has not occurred; a recent selective sweep (such as following drug treatment) might have resulted in the survival of one clone in a tumor originally showing a branched evolution pattern. Recent deep-sequencing analyses revealed that the majority of mutations are often found in just a fraction of tumor cells (reviewed in [3-5]). Such intratumor heterogeneity may have important clinical consequences, as it may affect biomarker validation and the emergence of drug resistance (reviewed in [6-9]). Therefore, understanding the drivers of intra-tumor heterogeneity and its maintenance has potential implications for the development of novel treatment strategies.

The evolution of population diversity has been studied extensively in the field of microbiology, using direct experimental approaches in which microbial populations have been followed over time to study evolutionary processes in action. Of particular relevance to this review, this approach has been used to successfully investigate 


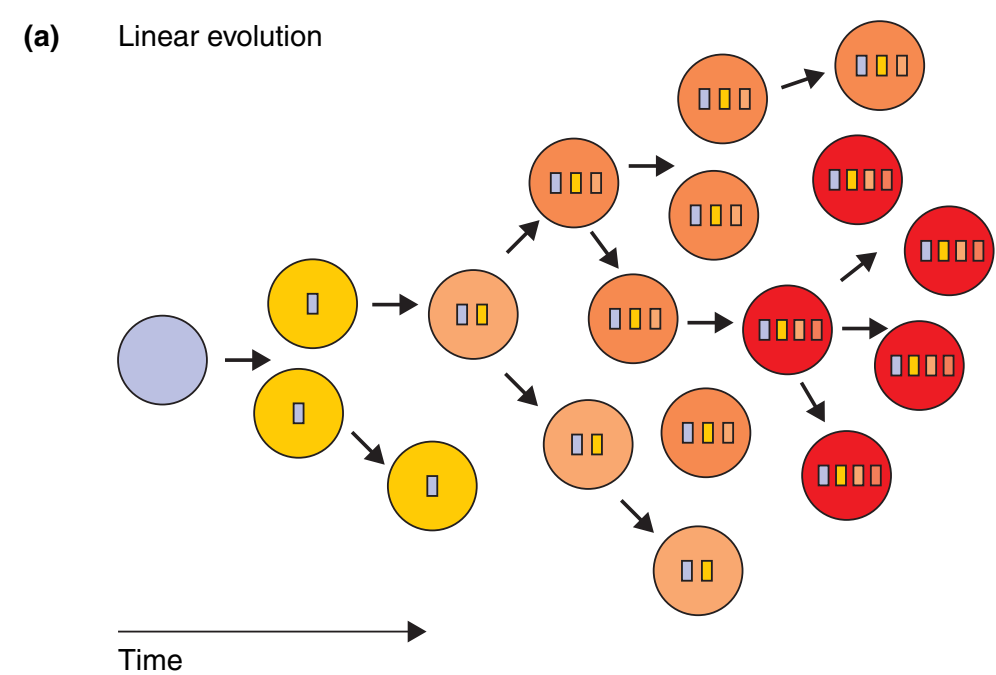

(b) Branched evolution

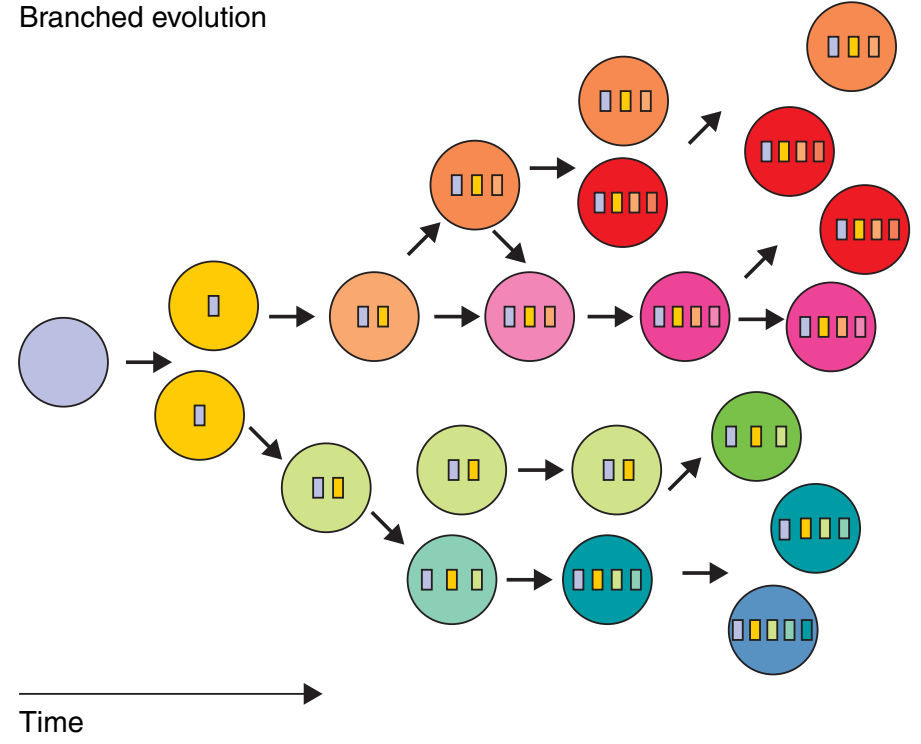

Figure 1 Schematic representation of linear and branched evolution patterns. The linear evolution model implies that each new subclone carries forward all the pre-existing mutations, whereas the branched evolution model implies that subclones expand independently and acquire different mutations over time. In this schematic representation, mutations are indicated by colors, with the previous mutations indicated in small squares within the new cell.

evolutionary drivers and dynamics of diversification, revealing important insights regarding the role of both biotic and abiotic factors. Here, we summarize the key drivers of diversity in microbial populations and discuss how these insights may be important for driving and maintaining intra-tumor heterogeneity.

\section{The spectrum of intra-tumor heterogeneity}

It is generally accepted that tumor tissues are heterogeneous. Pathologists often observe heterogeneity of morphological features within a tumor and therefore routinely examine multiple sections of a tumor to classify the tumor by its highest observed grade. Initial evidence of intra-tumor heterogeneity at a genetic level was provided by cytogenetic analyses. Karyotype analyses revealed multiple subclones carrying distinct chromosomal aberrations in several tumor types [10-12]. In addition, fluorescent in situ hybridization (FISH) experiments evaluating a specific region of the genome often showed heterogeneity in terms of copy number signals in different cells from one tumor (reviewed in [13]). Although having the advantage of single-cell analysis, a disadvantage of these studies is the limited number of markers that can be studied. Current genomic sequencing techniques, such as deep DNA sequencing, provide the opportunity to systematically analyze the complete 
Table 1 Summary of impact of biotic and abiotic environment on diversification in experimental evolution, with parallels in tumor biology

\begin{tabular}{llll}
\hline $\begin{array}{l}\text { Factors in } \\
\text { diversification }\end{array}$ & $\begin{array}{l}\text { Effect } \\
\text { on } \\
\text { diversity }\end{array}$ & Evolutionary theory & Observed patterns in oncology \\
\hline
\end{tabular}

\section{Biotic}

Mutation $\quad \uparrow \quad$ A higher mutation rate increases genetic variation and facilitates faster adaptation, with fitness cost as trade-off

Interspecific $\quad \uparrow \downarrow \quad$ Competitive intereactions may drive diversification interactions under weak selection. Under strong selection, bottlenecks may reduce diversity

$\uparrow \downarrow \quad$ Cooperative interactions drive diversification as structured environments mediate interactions between local cells creating heterogeneity across space

Intraspecific $\quad \uparrow \downarrow \quad$ In a heterogeneous environment, localized interactions interactions (competitive or cooperative) will increase diversity; in an homogenous environment, a single clone will tend to dominate

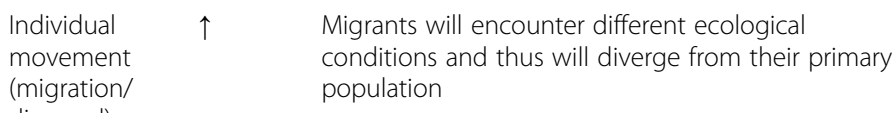

Genomic instability is an important source of genetic alterations (nucleotide mutations, deletions, amplifications and chromosomal rearrangements)

Tumor cells do interact with their environment, but the role of the microenvironment in driving genetic heterogeneity remains poorly understood

Tumors that grow at metastatic sites display organspecific genetic alterations, which might be due to microenvironmental differences

Intra-tumor heterogeneity exists at genotypic and a phenotypic levels (such as quiescent cells, differentiated cells, stem cells), which probably influence each other, in either a cooperative way (for example, generating specific niches) or a competitive way (for example, competition for limited resources or space)

Deep-sequencing data show that metastases do have unique mutations that are not detected in the primary tumor

dispersal)

A heterogenic environment provides multiple niches

Different subclones will be favored over time. A more rapidly changing environment will maintain more subclones

Exposure to antagonists tend to create bottlenecks, limiting diversity and favoring only resistant clones
Levels of oxygen and nutrients are not uniform throughout a tumor

A longitudinal study that included untreated CLL patients failed to observe a change in the relative presence of subclones in most cases within the time-frame of the study

Drug treatment can create a bottleneck, selecting the survival of less sensitive clones, thereby decreasing heterogeneity

$[5,6,23,24]$

$[8,25-32]$

genome on a large scale, resolving the extent of intratumor heterogeneity at unprecedented detail at the single-nucleotide level.

The extent of intra-tumor heterogeneity has been particularly revealed by studies that analyzed multiple spatially separated regions of one tumor. One of the first deep-sequencing studies that examined multiple primary tumor regions was presented by Yachida and colleagues [14]. They analyzed 426 somatic mutations in multiple regions of two pancreatic tumors and found regionally distinct subclones, each of which had expanded independently [14]. In a study by Gerlinger et al. [15], whole-exome sequencing of multiple spatially separated regions of four renal carcinomas revealed that only about a third of the non-synonymous somatic mutations were detectable in all regions of the tumor. Such a high level of intra-tumor heterogeneity implied that the regions diverged early during tumor evolution and continued to expand independently, following a branched evolution pattern (Figure 1b). Navin et al. [16] described similar findings at the DNA copy number level based on single-nucleus sequencing of different regions of two high-grade breast tumors. They identified several subpopulations in a tumor; although each subpopulation was related to the others by shared genomic alterations, the subpopulations had also diverged and developed unique alterations.

Several studies evaluated intra-tumor heterogeneity by deep-sequencing analysis of one sample per tumor. Although spatial separation is lost in this type of analysis, it estimates the level of intra-tumor heterogeneity by evaluating tumor clonality. Clonal mutations are shared by all cancer cells within the sample and thus are derived from a common ancestor, whereas subclonal mutations have occurred in a subset of cells. These studies often analyzed tumor samples from larger cohorts, and therefore could address the variation of intra-tumor heterogeneity within one tumor type rather than between tumors. In non-small-cell lung cancer samples, Govindan et al. [17] found that 10 of the 17 tumors (from 17 


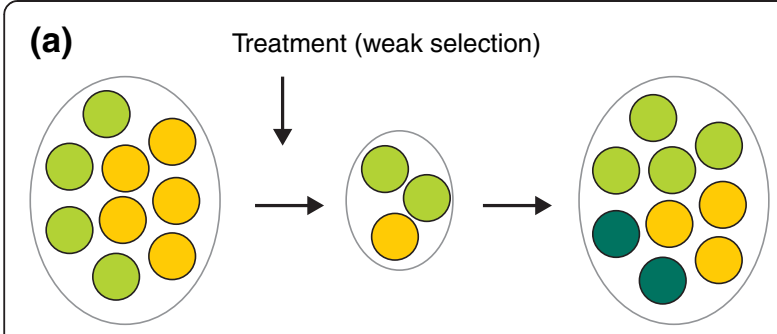

(b)

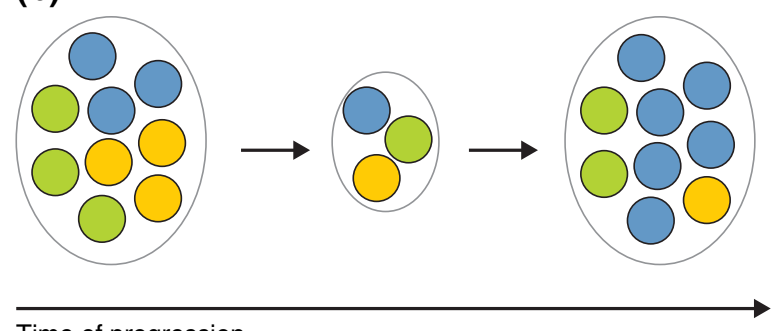

Time of progression

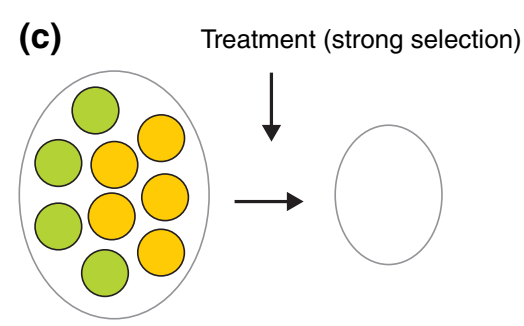

(d)

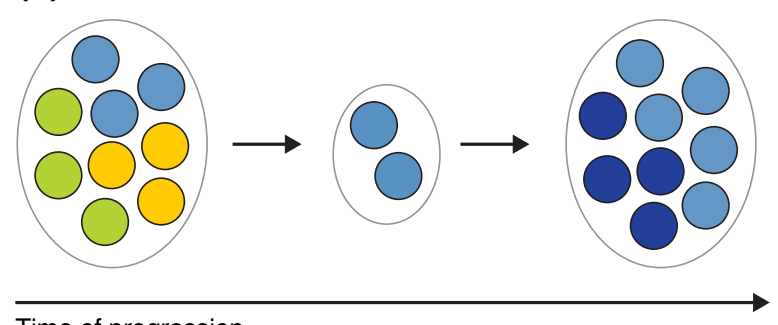

Resistance level:

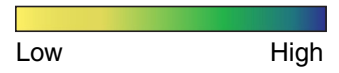

Figure 2 Schematic representation of how treatment affects tumor heterogeneity. A population of cells with various levels of competitive ability show differential responses to treatment, depending on the strength of the selection pressure imposed by the treatment and the heterogeneity present in the population. Treatment providing weak selection pressure $\mathbf{( a , b )}$ is expected to result in a balanced regrowth of the population that continues to progress when the heterogeneity is low (a); however, a reduction in population size offers opportunity for colonization and preferential growth of any aggressive clones that may be present in more heterogeneous populations (b). A strong selection pressure (c,d) will not allow clones with low-level tolerance to persist. Therefore, a homogeneous population that does not harbor a resistance mutation will respond well to strong treatment and population sizes are expected to dramatically reduce (c). However, heterogeneous populations are more likely to harbor cells with a mutation that confers resistance, and under strong selection these cells will be the only ones to survive. The subsequent population will no longer respond to treatment (d). In all cases, cells that survive treatment can acquire further mutations, this will be particularly important for resistant populations and the propensity for multidrug resistance.

different patients) showed a signature of multiple subclones. In triple-negative breast cancer, Shah et al. [18] observed that some tumors showed a wide spectrum of clonal frequencies, indicating multiple subclones, while others showed just one or two clonal frequency modes, suggesting a few subclones. Furthermore, a detailed analysis of 21 breast tumors [19,20] demonstrated subclonal mutations in all samples that often outnumbered the clonal mutations. And although some tumors showed a broad range of subclones, others showed fewer and more distinct subclonal expansions [20]. Altogether, these data revealed a broad range of intra-tumor heterogeneity, often supporting branched tumor evolution. Given that this might have major clinical implications, it is important to understand what fosters and drives such diversity in tumors.

\section{Insights from experimental microbial evolution}

Experimental evolution uses fast-replicating organisms (typically microorganisms) to study evolutionary processes in real time in a controlled laboratory environment. This allows hypothesis-driven experiments regarding the importance of controlled selective factors on the patterns and trajectory of an evolved trait of interest. Such studies have provided insights into what drives and maintains diversity with numerous mechanisms being identified $[21,22]$, revealing the important roles of both the biotic factors (living properties) and the abiotic factors (nonliving chemical and physical properties) in creating ecological opportunities for diversification (Table 1).

\section{Biotic factors}

Biotic factors include all biological factors such as mutation rate, cell-to-cell interactions and cell movement (migration and dispersal). Mutation rate is likely to be important in tumor heterogeneity and therefore deserves special attention. For diversity to evolve, variation must exist in a population, and the source of this variation will be determined by genetic factors, including point mutations and genomic rearrangements. Most genetic alterations will be deleterious and purged from the population (or maintained at low frequencies) but, in rare cases, these mutations will provide a fitness advantage - fueling adaptive evolution. Therefore, a high mutation rate (number of 
genetic mutations over time) will increase the potential for adaptive evolution by increasing the variation on which natural selection can act. This concept is clearly discussed in the classic 1932 paper by Sewall Wright [46], in which he describes that mutations provide a system of 'trial and error' for individuals within a population that enables them to explore the potential for adaptation within an environment. Moreover, we must also consider how the spread of these mutations will be affected by population size, with changes in allele frequencies in small populations governed more by chance (genetic drift) than in large populations, in which the strength of selection will have a larger role [47].

Experimental evolution studies with microorganisms (typically bacteria [48] and yeast [49]) have shown that populations with greater variation adapt more quickly than those that are genetically homogenous, and heterogeneous populations thus fare better in stressful or rapidly changing environments $[50,51]$. However, there is an important trade-off to consider, as an increased mutation rate will come at the cost of increased mutational load [52], in which the random deleterious mutations accumulate in the genome, conferring a large fitness cost. This effect can be so severe that populations can be driven to extinction, in a process called mutational meltdown $[49,53,54]$.

The effect that the mutation rate has on adaptation and diversification will depend on the strength of selection (Figure 2) [23]. If beneficial mutations under strong selection occur rarely, we would expect selective sweeps to drive these mutations to fixation, resulting in low diversity and a linear evolution pattern. However, if beneficial mutations under strong selection occur frequently, they will coexist within a population (without sweeping to fixation); this can increase population diversity and result in a branched evolution pattern $[55,56]$. On the other hand, weak selection can drive diversity through the accumulation of small-effect deleterious mutations [57], with detrimental overall population fitness effects unless coupled with a sufficient gain of beneficial mutations to counterbalance this effect [58].

Another biotic factor that can influence population diversification is cell-to-cell interaction, and this can be either competitive (interaction will come at a cost), or cooperative (beneficial for all individuals involved in the interaction). In evolutionary studies, there is evidence for both types of interaction, with opposing consequences for diversification. In a recent study, Bailey et al. [59] investigated the impact of both intraspecific (within-species) and interspecific (between-species) competitive interactions on the diversification of the model bacterium Pseudomonas fluorescens when competition for resources was high (strength of competition was strong), with variable opportunity for diversification.
They found that intraspecific competition was positively correlated with diversification, whereas strong interspecific competitors were able to prevent diversification through niche exclusion; however, weak interspecific competitors actually promoted diversification by increasing the strength of intraspecific competition [59]. This study exemplifies the importance of context when considering how the local competitive environment is likely to influence diversification - and the predictions are unlikely to be clear cut. In general, competitive interactions will be determined by the strength of competition and the ability of the competitors to diversify.

As with competitive interactions, the consequences of cooperative interactions will depend on whether they are within or between species. In general, cooperative interactions between interspecifics are considered to increase diversity because both will be maintained in the population, as both gain a benefit from the interaction, whereas intraspecific interactions are more likely to depend on the structure of the environment [60-62]. Experimental evolution studies have found that structured environments are more likely to sustain multiple cooperating clones, whereas in unstructured environments, fewer clones will dominate [61].

The movement of individuals between different populations (migration) and to new sites (dispersal) has the potential to increase gene flow between populations and therefore increase diversity, either through the introduction of new genetically distant individuals into a population or through the expansion of a population through colonization of a new patch, where niche specialization can occur and thus populations can diverge [36].

\section{Abiotic factors}

Abiotic factors include all non-living and physical factors from the environment. A heterogeneous environment may vary in either space or time (or both), creating distinct niches within a single population. Distinct niches, differentiated by the physical environment [38] (for example, habitat structure, quality and so on) or the competitive environment (for example, individuals competing for similar/different resources), create a trade-off between competitive advantages in one environment against another, thus increasing and maintaining overall population diversity $[63,64]$. Indeed, Rainey and Travisano [38] have shown that diversity in a bacterial population evolved rapidly in a spatially heterogeneous, but not spatially homogeneous environment. It was recently shown that such niche specialization can be caused by a self-generated oxygen gradient [65]. Furthermore, a structured, competitive environment where resources are limited will favor genotypes that are not in direct competition with a 
dominant genotype, that is, that occupy slightly different, untapped niches $[33,38,66,67]$.

Moreover, we must consider how 'non-living antagonists' (in the specific case of cancer this refers to drug treatment) might influence the diversification of a population. Exposure to drugs in the first instance is likely to create a bottleneck, favoring the few clones that may randomly possess a mutation that confers resistance to the drug. There is evidence from both microbial [68] and cancer cell populations (discussed below) that drug treatments can reduce heterogeneity of a population when they are naive to the drug.

\section{Parallels with potential drivers of diversity in tumors}

As we have discussed above, both genetic and environmental factors influence microbial population diversification, and the current challenge is to understand how these factors translate to intra-tumor heterogeneity.

\section{Biotic factors}

In tumors, genomic instability (mutations and chromosomal rearrangements) is an important characteristic that fosters tumorigenesis [69]. Mechanisms that maintain genome stability are often lost in tumor cells, and exposure to DNA-damaging agents, such as ultraviolet radiation or smoking, will increase the mutation rate. Such genomic instability is likely to increase heterogeneity within a tumor, as discussed in several recent reviews $[6,25,70]$.

Evidence that the classical trade-off observed in microbial experimental populations - that a high mutation rate facilitates rapid adaptation but at the cost of increased mutational load - can also be relevant in tumors is based on findings on chromosomal instability. This instability is typically associated with poor patient prognosis and is found to mediate intrinsic multidrug resistance [71]. However, further investigations revealed that extreme levels of chromosomal instability were associated with improved prognosis [72]. These results suggest that an intermediate level of genome instability confers the highest fitness to tumor cells, which could be due to the trade-off between adaptability and accumulation of deleterious effects associated with an elevated mutation rate, analogous to mutational meltdown. Understanding of such trade-offs in cancer might help us to develop or improve current treatment strategies.

It is evident that tumor cells interact with cells in their close environment. As such, the tumor microenvironment (such as fibroblasts, vasculature and immune cells) can create local differences that have an impact on the organization and progression of the tumor (Table 1; analogous to interspecific interactions between microorganisms) [26-28]. In addition, recent reviews regarding drug resistance have drawn a parallel between bacterial populations and tumor cells and suggested that heterogeneity in treatment response is, at least partly, due to heterogeneity in the tumor microenvironment $[8,29,73]$. Anderson et al. [74] explored in silico the effect of both cellular and environmental factors on tumor progression, and their model predicted that a 'mild' microenvironment (resulting in weak selection pressure) would enable the coexistence of many different subclones within a tumor, whereas a harsh environment would select a few more aggressive clones, similar to what has been observed in microbial populations (Figure 2).

Evidence that different microenvironments have different selective pressures that could result in heterogeneity at the genetic level was provided by recent deepsequencing analyses of multiple metastatic sites of pancreatic tumors [37]. This study revealed specific DNA arrangements in lung metastases that differed from those identified in abdominal metastases. These data indicate that the different organs exerted a different selective pressure; they either attracted different tumor cells or the metastatic tumor cells evolved differently as a result of microenvironmental differences.

In addition, if structure of the 'interspecific' (with other cell types) and 'intraspecific' (with tumor cells) tumor cell interactions promoted heterogeneity within a tumor population, we may expect to detect more heterogeneity in solid than in hematological tumors: because solid tumors grow in a restrictive environment, there will be greater cell-cell competition for resources, such as space and nutrients. Indeed, several recent studies $[30,75,76]$ reviewed the frequency of copy number alterations and somatic mutations across multiple tumor types and found that solid tumors show a higher level of both compared with hematological tumors. In addition, a recently published deep-sequencing study on the progression of a hematological cancer (from myelodysplastic syndrome to acute myeloid leukemia (AML)) [77] identified various subclones in the AML cells, but in such a way that each new subclone carried forward all the preexisting mutations, indicating a linear evolution pattern instead of a branched evolution pattern (Figure 1). These data suggest that intraspecific tumor cell interactions can have a role in driving heterogeneity (Table 1), but that other factors are also involved.

\section{Abiotic factors}

It is harder to separate biotic and abiotic factors in the context of tumors, as their environment is a living organism, and thus by definition a biotic environment. However, the tumor environment can vary in space in terms of access to nutrients because of uneven vascularization $[39,40]$ and in terms of diffusion of drugs through a solid tumor mass [41]. In addition, time and 
especially exposure to non-living antagonists (such as therapeutic drugs) are thought to affect intra-tumor heterogeneity.

We are not aware of longitudinal studies in untreated solid tumors. However, a recent longitudinal study of leukemia (CLL) did include six untreated patients [42]. When two samples were taken from each patient with a median time interval of 3.7 years between the first and repeat sample, five of these six paired samples maintained the relative presence of the subclones. The authors speculate that more time might be required for a new clone to take over the population [42]. This is in contrast with leukemia samples treated with cytotoxic chemotherapy, as shown in the same and another study $[42,44]$. Analyzing CLL and AML, respectively, both studies showed that a subset of clones had disappeared in the post-treatment sample, while other subclones expanded and acquired new mutations, indicating that these subclones survived better during treatment and showed rapid outgrowth (as in Figure 2d). Nevertheless, a minority of CLL tumors maintained the subclonal equilibrium during treatment [42]. These data indicate that the treatment functioned as a strong selective pressure in the majority of tumors, resulting in a bottleneck effect, but not in all tumors, and the underlying cause of this differential response is currently unclear.

\section{Implications of intra-tumor heterogeneity for clinical outcome}

Evolutionary studies suggest that populations with greater genetic variation will adapt faster than clonal populations, because beneficial mutations are more likely to already be present in the population, rather than needing to occur de novo within the population [78]. Therefore, it is predicted that genetic variation is particularly important for organisms that must adapt quickly to a stressful and rapidly changing environment. Such stressful change occurs for a tumor, for example, during drug treatment, and several reviews have compared the emergence of drug-resistant tumor cells to the emergence of antibiotic-resistant bacteria $[8,29,73]$. In parallel to bacterial studies, it would be interesting to see whether the effect of the treatment depends on drug dose in combination with the extent of intra-tumor heterogeneity (Figure 2). An important finding in the CLL study described above [42] was that the subclonal, rather than the clonal, driver mutations present in the pretreatment sample were associated with poorer treatment response. This observation supports the notion that a higher level of intra-tumor heterogeneity can enhance the development of drug resistance. In addition, chromosomal instability, a potential driver of intratumor heterogeneity, is typically associated with poor prognosis in solid and in hematological tumors [70]. It is currently unclear if this is the result of drug-resistant subclones already present in the tumor, or if tumors with more subclones have a higher capacity to adapt to a new environment because of, for example, enhanced genetic instability.

Interestingly, a reversion of a drug-resistant tumor to a drug-sensitive one has been described for two lung cancer patients treated with an epidermal growth factor receptor (EGFR) inhibitor. A second mutation in EGFR (T790M) resulting in resistance was initially detected in the resistant sample but after an interval without the inhibitor, this mutation was no longer detectable and the tumors became responsive again [79]. This suggests that the cells harboring a T790M mutation were outcompeted by cells that did not harbor such mutation in the absence of the inhibitor. Another study showed that cells that acquired a T790M mutation by long-term culture in the presence of drugs in vitro had a reduced proliferation rate compared with the parental cells [80]. Nevertheless, as the T790M mutation has been detected in tumors in the absence of the drug, albeit at low frequency, and has been shown to enhance EGFR activity in experiments in vitro [81-83], it is currently unclear whether the reduced growth rate is due to the T790M mutation itself or to other mutations that might have occurred at the same time. This involves resistance to a kinase inhibitor with a specific resistance mechanism (EGFR-T790M), which is different from resistance to chemotherapeutic agents. Exploring these differences might provide an opportunity to understand the finer details of the evolved resistance mechanisms.

From a clinical perspective, the above discussion would imply that, in order to prevent the outgrowth of resistant clones that would be likely to acquire secondary beneficial mutations to compensate for the initial costs of resistance, drug treatment should be adjusted as soon as resistant clones emerge in the population. Indeed, such an adaptive strategy has been proposed and successfully studied in xenograft models; in these models, a population of treatment-sensitive cells was maintained so as to suppress the growth of the less fit but resistant cells through intra-tumor competition $[84,85]$. However, proof of this principle in cancer patients is not yet available, and a major challenge will be the early detection of resistant clones, as these will initially be present at very low frequency when they first emerge in the population. Using a standard biopsy to evaluate the tumor may miss these clones until they are present at greater number - making early detection more difficult. A major challenge is that compensatory mutations will most likely emerge while the resistant clones are rare, and once the cost of resistance has been compensated for, these resistant clones will increase in frequency within the population. In the case of resistance 
to EGFR kinase inhibitors, an alternative approach of pulsed high doses of inhibitors has been proposed, which did delay the outgrowth of resistant clones to EGFR kinase inhibitors in an experimental setting [80]. Another crucial question that must be addressed with such a treatment method is whether all resistant mutations are, in fact, associated with a fitness cost, or only some mutations. It would be hasty to assume that all resistance mutations carry a cost without accurately measuring the fitness effects of each, and studies that categorically address this question are becoming urgently necessary.

Overall, care must be taken not to draw too close parallels between microbial and cancer systems in terms of resistance mechanisms. There are many factors to consider that have the potential to alter standard predictions made from unicellular models, and these differences may be key in tumor progression. In particular, we are likely to find major differences in the evolution of drug resistance in tumors, because in contrast to antibiotics that target a specific pathogen, tumor cells are derived from normal cells and share many of their characteristics, thereby limiting the drug dose and combinations of drugs that can be used in the clinic owing to adverse side-effects. Nevertheless, important insights can be gained from experimental evolution with microbes if we focus on the population genetics of evolved resistance in terms of the spread of alleles given certain selection pressures and costs of resistance in certain given microenvironments. There is a pressing need for hypothesisdriven and rigorously designed experiments alongside longitudinal studies that address whether intra-tumor heterogeneity drives clinically important cancer characteristics, such as invasiveness, metastatic potential and the evolution of drug resistance.

\section{Conclusions and future perspectives}

The extent of genetic intra-tumor heterogeneity is becoming clearer as a result of recent deep-sequencing approaches. Experimental evolution has taught us important lessons about the evolution and maintenance of diversity within populations. By using and applying these general theories to cancer evolution, we can draw parallels and make predictions as to which selective factors may be most important during tumor progression. As summarized in Table 1, genetic instability and interactions with other tumor cells (intraspecific) and the microenvironment (biotic and abiotic) are expected to have a role in driving and maintaining heterogeneity. However, although many of the issues considered in this review have been successfully addressed using experimental evolution in microbes, tumors present new challenges because of their increased complexity and multicellular existence. The general insight that microbial studies offer into fundamental evolutionary processes is therefore where useful comparisons and predictions can be made in tumors. Techniques from experimental evolution could be useful in the context of tumor biology to systematically quantify mutation rates and evaluate costs of resistance (at least in vitro) and determine the role of the microenvironment in diversification. This will improve the predictive power of evolutionary trajectories and potential drug resistance profiles during tumor progression.

Fortunately, tumors share many beneficial characteristics with microbial model systems that make them ideal for experimental evolution studies [86]. Conveniently, laboratory-adapted microbes and tumor cell lines can be relatively easily followed over time, enabling accurate measurements of mutation rates and prediction of associated consequences for tumor progression and prognosis. And to account for the differences between microbes and cancers, future experimental studies need to be conducted to explicitly test evolutionary theory within the context of cancer. Accurately measuring mutation rates and cell consequences in vivo will be more challenging in the case of tumors, with limited material and often no longitudinal follow-up. Nevertheless, detection methods are becoming more sensitive, allowing timing estimates of progression of a tumor sample [14], and several surrogate markers have been described, as recently reviewed [30].

Many questions regarding the importance of intratumor heterogeneity in tumor progression remain to be addressed in a systematic way, such as its impact on drug resistance, metastatic capacity and survival outcome. Satisfactorily addressing these questions is not a trivial task, requiring novel and innovative research approaches. Initially, there is an urgent need for detailed longitudinal studies that follow the level and shape of intra-tumor heterogeneity over time. Such studies will enable us to evaluate whether levels of intra-tumor heterogeneity correlate with clinical outcome - with the hypothesis that heterogeneous tumors have a higher chance of containing or acquiring a cell that has the ability to metastasize or to be intrinsically drug resistant, while acknowledging that excessive genomic instability may be deleterious for cancer growth and progression [87].

Longitudinal data collection from solid tumors may prove challenging. However, recent developments in the ability to deep-sequence circulating tumor DNA offers a promising approach to following the tumor landscape in a non-invasive manner $[55,88]$. Together with the evaluation of tumor behavior, the expectation is that such longitudinal studies might also provide insights into potential drivers of intra-tumor heterogeneity, which can be investigated in more detail using the insights from the field of microbial experimental evolution. 


\section{Abbreviations}

AML: acute myeloid leukemia; CLL: chronic lymphocytic leukemia; EGFR: epithelial growth factor receptor

\section{Competing interests}

The authors declare that they have no competing interests.

\section{Acknowledgments}

We thank Britt Koskella and Michael Brockhurst for critical reading and helpful comments on earlier versions of this manuscript.

\section{Author details}

${ }^{1}$ Translational Cancer Therapeutics Lab, UCL Cancer Institute, University College London, London WC1E 6DD, UK. ${ }^{2}$ School of Biological Sciences, University of Reading, Whiteknights, Reading, Berkshire RG6 6AH, UK. ${ }^{3}$ Translational Cancer Therapeutics Lab, Cancer Research UK London Research Institute, London WC2A 3LY, UK.

Published: 22 November 2013

\section{References}

1. Nowell PC: The clonal evolution of tumor cell populations. Science 1976 194:23-28.

2. Polyak K: Is breast tumor progression really linear? Clin Cancer Res 2008, 14:339-341

3. Yates $L R$, Campbell PJ: Evolution of the cancer genome. Nat Rev Genet 2012, 13:795-806

4. Horswell S, Matthews N, Swanton C: Cancer heterogeneity and "The Struggle for Existence": Diagnostic and analytical challenges. Cancer Lett 2012.

5. Swanton C: Intratumor heterogeneity: evolution through space and time. Cancer Res 2012, 72:4875-4882.

6. Burrell RA, McGranahan N, Bartek J, Swanton C: The causes and consequences of genetic heterogeneity in cancer evolution. Nature 2013, 501:338-345.

7. Gerlinger M, Swanton C: How Darwinian models inform therapeutic failure initiated by clonal heterogeneity in cancer medicine. $\mathrm{Br} J$ Cancer 2010, 103:1139-1143.

8. Junttila MR, de Sauvage FJ: Influence of tumour micro-environment heterogeneity on therapeutic response. Nature 2013, 501:346-354.

9. Murugaesu N, Chew SK, Swanton C: Adapting clinical paradigms to the challenges of cancer clonal evolution. Am J Pathol 2013, 182:1962-1971.

10. Gorunova L, Hoglund M, Andren-Sandberg A, Dawiskiba S, Jin Y, Mitelman F, Johansson B: Cytogenetic analysis of pancreatic carcinomas: intratumor heterogeneity and nonrandom pattern of chromosome aberrations. Genes Chromosomes Cancer 1998, 23:81-99.

11. Teixeira MR, Heim S: Cytogenetic analysis of tumor clonality. Adv Cancer Res 2011, 112:127-149.

12. Teixeira MR, Pandis N, Bardi G, Andersen JA, Heim S: Karyotypic comparisons of multiple tumorous and macroscopically normal surrounding tissue samples from patients with breast cancer. Cancer Res 1996, 56:855-859.

13. Navin NE, Hicks J: Tracing the tumor lineage. Mol Oncol 2010, 4:267-283.

14. Yachida S, Jones S, Bozic I, Antal T, Leary R, Fu B, Kamiyama M, Hruban RH, Eshleman JR, Nowak MA, Velculescu VE, Kinzler KW, Vogelstein B, lacobuzioDonahue CA: Distant metastasis occurs late during the genetic evolution of pancreatic cancer. Nature 2010, 467:1114-1117.

15. Gerlinger M, Rowan AJ, Horswell S, Larkin J, Endesfelder D, Gronroos E, Martinez P, Matthews N, Stewart A, Tarpey P, Varela I, Phillimore B, Begum S, McDonald NQ, Butler A, Jones D, Raine K, Latimer C, Santos CR, Nohadani M, Eklund AC, Spencer-Dene B, Clark G, Pickering L, Stamp G, Gore M, Szallasi Z, Downward J, Futreal PA, Swanton C: Intratumor heterogeneity and branched evolution revealed by multiregion sequencing. $N$ Engl J Med 2012, 366:883-892.

16. Navin N, Kendall J, Troge J, Andrews P, Rodgers L, Mclndoo J, Cook K, Stepansky A, Levy D, Esposito D, Muthuswamy L, Krasnitz A, McCombie WR, Hicks J, Wigler M: Tumour evolution inferred by single-cell sequencing. Nature 2011, 472:90-94.

17. Govindan R, Ding L, Griffith M, Subramanian J, Dees ND, Kanchi KL, Maher CA, Fulton R, Fulton L, Wallis J, Chen K, Walker J, McDonald S, Bose R, Ornitz D, Xiong D, You M, Dooling DJ, Watson M, Mardis ER, Wilson RK: Genomic landscape of non-small cell lung cancer in smokers and never-smokers. Cell 2012, 150:1121-1134.

18. Shah SP, Roth A, Goya R, Oloumi A, Ha G, Zhao Y, Turashvili G, Ding J, Tse K, Haffari G, Bashashati A, Prentice LM, Khattra J, Burleigh A, Yap D, Bernard V McPherson A, Shumansky K, Crisan A, Giuliany R, Heravi-Moussavi A, Rosner J, Lai D, Birol I, Varhol R, Tam A, Dhalla N, Zeng T, Ma K, Chan SK, et al: The clonal and mutational evolution spectrum of primary triple-negative breast cancers. Nature 2012, 486:395-399.

19. Nik-Zainal S, Alexandrov LB, Wedge DC, Van Loo P, Greenman CD, Raine K, Jones D, Hinton J, Marshall J, Stebbings LA, Menzies A, Martin S, Leung K, Chen L, Leroy C, Ramakrishna M, Rance R, Lau KW, Mudie LJ, Varela I, McBride DJ, Bignell GR, Cooke SL, Shlien A, Gamble J, Whitmore I, Maddison M, Tarpey PS, Davies HR, Papaemmanuil E, et al: Mutational processes molding the genomes of 21 breast cancers. Cell 2012, 149:979-993.

20. Nik-Zainal S, Van Loo P, Wedge DC, Alexandrov LB, Greenman CD, Lau KW Raine K, Jones D, Marshall J, Ramakrishna M, Shlien A, Cooke SL, Hinton J, Menzies A, Stebbings LA, Leroy C, Jia M, Rance R, Mudie LJ, Gamble SJ, Stephens PJ, McLaren S, Tarpey PS, Papaemmanuil E, Davies HR, Varela I, McBride DJ, Bignell GR, Leung K, Butler AP, et al: The life history of 21 breast cancers. Cell 2012, 149:994-1007.

21. Maharjan RP, Ferenci T, Reeves PR, Li Y, Liu B, Wang L: The multiplicity of divergence mechanisms in a single evolving population. Genome Biol 2012, 13:R41.

22. Kassen $\mathrm{R}$ : The experimental evolution of specialists, generalists, and the maintenance of diversity. J Evol Biol 2002, 15:173-190.

23. Chao L, Cox EC: Competition between high and low mutating strains of Escherichia coli. Evolution 1983, 37:125-134.

24. Loeb LA: A mutator phenotype in cancer. Cancer Res 2001, 61:3230-3239.

25. Sprouffske K, Merlo LM, Gerrish PJ, Maley CC, Sniegowski PD: Cancer in light of experimental evolution. Curr Biol 2012, 22:R762-R771.

26. Calvo F, Sahai E: Cell communication networks in cancer invasion. Cur Opin Cell Biol 2011, 23:621-629.

27. Lu P, Weaver VM, Werb Z: The extracellular matrix: a dynamic niche in cancer progression. J Cell Biol 2012, 196:395-406.

28. Qian BZ, Pollard JW: Macrophage diversity enhances tumor progression and metastasis. Cell 2010, 141:39-51.

29. Lambert G, Estevez-Salmeron L, Oh S, Liao D, Emerson BM, Tlsty TD, Austin $\mathrm{RH}$ : An analogy between the evolution of drug resistance in bacterial communities and malignant tissues. Nat Rev Cancer 2011, 11:375-382.

30. Pikor L, Thu K, Vucic E, Lam W: The detection and implication of genome instability in cancer. Cancer Metastasis Rev 2013. doi: 0.1007/s10555-0139429-5.

31. Schluter D: Experimental evidence that competition promotes divergence in adaptive radiation. Science 1994, 266:798-801.

32. Straussman R, Morikawa T, Shee K, Barzily-Rokni M, Qian ZR, Du J, Davis A, Mongare MM, Gould J, Frederick DT, Cooper ZA, Chapman PB, Solit DB, Ribas A, Lo RS, Flaherty KT, Ogino S, Wargo JA, Golub TR: Tumour microenvironment elicits innate resistance to RAF inhibitors through HGF secretion. Nature 2012, 487:500-504.

33. Kerr B, Riley MA, Feldman MW, Bohannan BJ: Local dispersal promotes biodiversity in a real-life game of rock-paper-scissors. Nature 2002, 418:171-174.

34. Medema JP: Cancer stem cells: the challenges ahead. Nat Cell Biol 2013, 15:338-344

35. Visvader JE, Lindeman GJ: Cancer stem cells in solid tumours: accumulating evidence and unresolved questions. Nature Rev Cancer 2008, 8:755-768.

36. Ronce $\mathrm{O}$, Kirkpatrick M: When sources become sinks: migrational meltdown in heterogeneous habitats. Evolution 2001, 55:1520-1531.

37. Campbell PJ, Yachida S, Mudie LJ, Stephens PJ, Pleasance ED, Stebbings LA Morsberger LA, Latimer C, McLaren S, Lin ML, McBride DJ, Varela I, NikZainal SA, Leroy C, Jia M, Menzies A, Butler AP, Teague JW, Griffin CA, Burton J, Swerdlow H, Quail MA, Stratton MR, lacobuzio-Donahue C, Futreal PA: The patterns and dynamics of genomic instability in metastatic pancreatic cancer. Nature 2010, 467:1109-1113.

38. Rainey PB, Travisano M: Adaptive radiation in a heterogeneous environment. Nature 1998, 394:69-72.

39. Vaupel P, Hockel M: Blood supply, oxygenation status and metabolic micromilieu of breast cancers: characterization and therapeutic relevance. Int J Oncol 2000, 17:869-879. 
40. Vaupel $P$, Kallinowski F, Okunieff $P$ : Blood flow, oxygen and nutrient supply, and metabolic microenvironment of human tumors: a review. Cancer Res 1989, 49:6449-6465.

41. Olive KP, Jacobetz MA, Davidson CJ, Gopinathan A, McIntyre D, Honess D, Madhu B, Goldgraben MA, Caldwell ME, Allard D, Frese KK, Denicola G, Feig C, Combs C, Winter SP, Ireland-Zecchini H, Reichelt S, Howat WJ, Chang A, Dhara M, Wang L, Rückert F, Grützmann R, Pilarsky C, Izeradjene K, Hingorani SR, Huang P, Davies SE, Plunkett W, Egorin M, et al: Inhibition of Hedgehog signaling enhances delivery of chemotherapy in a mouse model of pancreatic cancer. Science 2009, 324:1457-1461.

42. Landau DA, Carter SL, Stojanov P, McKenna A, Stevenson K, Lawrence MS, Sougnez C, Stewart C, Sivachenko A, Wang L, Wan Y, Zhang W, Shukla SA, Vartanov A, Fernandes SM, Saksena G, Cibulskis K, Tesar B, Gabriel S, Hacohen N, Meyerson M, Lander ES, Neuberg D, Brown JR, Getz G, Wu CJ: Evolution and impact of subclonal mutations in chronic lymphocytic leukemia. Cell 2013, 152:714-726

43. Descamps-Julien B, Gonzalez A: Stable coexistence in a fluctuating environment: an experimental demonstration. Ecology 2005, 86:28152824.

44. Ding L, Ley TJ, Larson DE, Miller CA, Koboldt DC, Welch JS, Ritchey JK, Young MA, Lamprecht T, McLellan MD, McMichael JF, Wallis JW, Lu C, Shen D, Harris CC, Dooling DJ, Fulton RS, Fulton LL, Chen K, Schmidt H, KalickiVeizer J, Magrini VJ, Cook L, McGrath SD, Vickery TL, Wendl MC, Heath S, Watson MA, Link DC, Tomasson MH, et al: Clonal evolution in relapsed acute myeloid leukaemia revealed by whole-genome sequencing. Nature 2012, 481:506-510

45. Levin BR, Lipsitch M, Perrot V, Schrag S, Antia R, Simonsen L, Walker NM, Stewart FM: The population genetics of antibiotic resistance. Clin Infect Dis 1997, 24:S9-S16.

46. Wright $\mathrm{S}$ : The roles of mutation, inbreeding, crossbreeding and selection in evolution. Proc Sixth Int Congress Genet 1932, 1:356-366.

47. Wright S: Evolution and the Genetics of Populations, Volume 3. Chicago: University of Chicage Press; 1977.

48. Lenski RE, Travisano M: Dynamics of adaptation and diversification: a 10,000-generation experiment with bacterial populations. Proc Natl Acad Sci U S A 1994, 91:6808-6814

49. Zeyl C, Mizesko M, de Visser JA: Mutational meltdown in laboratory yeast populations. Evolution 2001, 55:909-917.

50. Buckling A, Kassen R, Bell G, Rainey PB: Disturbance and diversity in experimental microcosms. Nature 2000, 408:961-964.

51. Massey RC, Buckling A: Environmental regulation of mutation rates at specific sites. Trends Microbiol 2002, 10:580-584.

52. Andersson DI: Persistence of antibiotic resistant bacteria. Curr Opin Microbiol 2003, 6:452-456.

53. Lynch M, Burger R, Butcher $D$, Gabriel W: The mutational meltdown in asexual populations. J Hered 1993, 84:339-344.

54. Soll SJ, Diaz Arenas C, Lehman N: Accumulation of deleterious mutations in small abiotic populations of RNA. Genetics 2007, 175:267-275.

55. Desai MM, Fisher DS: Beneficial mutation selection balance and the effect of linkage on positive selection. Genetics 2007, 176:1759-1798.

56. Gerrish PJ, Lenski RE: The fate of competing beneficial mutations in an asexual population. Genetica 1998, 102-103:127-144.

57. Gudelj I, Weitz JS, Ferenci T, Claire Horner-Devine M, Marx CJ, Meyer JR, Forde SE: An integrative approach to understanding microbial diversity: from intracellular mechanisms to community structure. Ecol Lett 2010, 13:1073-1084

58. Loewe L, Hill WG: The population genetics of mutations: good, bad and indifferent. Philos Trans R Soc Lond B Biol Sci 2010, 365:1153-1167.

59. Bailey SF, Dettman JR, Rainey PB, Kassen R: Competition both drives and impedes diversification in a model adaptive radiation. Proc Biol Sci 2013, 280:20131253

60. Harcombe W: Novel cooperation experimentally evolved between species. Evolution 2010, 64:2166-2172.

61. Nadell CD, Foster KR, Xavier JB: Emergence of spatial structure in cell groups and the evolution of cooperation. PLoS Comp Biol 2010, 6: e1000716.

62. Verbruggen E, El Mouden C, Jansa J, Akkermans G, Bucking H, West SA, Kiers ET: Spatial structure and interspecific cooperation: theory and an empirical test using the mycorrhizal mutualism. Am Nat 2012, 179:E133-E146.

63. Spiers AJ, Buckling A, Rainey PB: The causes of Pseudomonas diversity. Microbiology 2000, 146:2345-2350.
64. Herron MD, Doebeli M: Parallel evolutionary dynamics of adaptive diversification in Escherichia coli. PLOS Biol 2013, 11:e1001490.

65. Koza A, Moshynets O, Otten W, Spiers AJ: Environmental modification and niche construction: developing $\mathrm{O} 2$ gradients drive the evolution of the Wrinkly Spreader. ISME J 2011, 5:665-673.

66. Helling RB, Vargas CN, Adams J: Evolution of Escherichia coli during growth in a constant environment. Genetics 1987, 116:349-358.

67. Le Gac M, Plucain J, Hindre T, Lenski RE, Schneider D: Ecological and evolutionary dynamics of coexisting lineages during a long-term experiment with Escherichia coli. Proc Natl Acad Sci U S A 2012, 109:9487-9492.

68. Flanagan JL, Brodie EL, Weng L, Lynch SV, Garcia O, Brown R, Hugenholtz P, DeSantis TZ, Andersen GL, Wiener-Kronish JP, Bristow J: Loss of bacterial diversity during antibiotic treatment of intubated patients colonized with Pseudomonas aeruginosa. J Clin Microbiol 2007, 45:1954-1962.

69. Hanahan D, Weinberg RA: Hallmarks of cancer: the next generation. Cell 2011, 144:646-674.

70. McGranahan N, Burrell RA, Endesfelder D, Novelli MR, Swanton C: Cancer chromosomal instability: therapeutic and diagnostic challenges. EMBO Rep 2012, 13:528-538.

71. Lee A, Endesfelder D, Rowan A, Walther A, Birkbak N, Futreal AP, Downward J, Szallasi Z, Tomlinson I, Kschischo M, Swanton C: Chromosomal instability confers intrinsic multi-drug resistance. Cancer Res 2011, 71:1858-1870.

72. Birkbak NJ, Eklund AC, Li Q, McClelland SE, Endesfelder D, Tan P, Tan IB, Richardson AL, Szallasi Z, Swanton C: Paradoxical relationship between chromosomal instability and survival outcome in cancer. Cancer Res 2011, 71:3447-3452.

73. Glickman MS, Sawyers CL: Converting cancer therapies into cures: lessons from infectious diseases. Cell 2012, 148:1089-1098.

74. Anderson AR, Weaver AM, Cummings PT, Quaranta V: Tumor morphology and phenotypic evolution driven by selective pressure from the microenvironment. Cell 2006, 127:905-915.

75. Loeb LA: Human cancers express mutator phenotypes: origin, consequences and targeting. Nat Rev Cancer 2011, 11:450-457.

76. Kandoth C, McLellan MD, Vandin F, Ye K, Niu B, Lu C, Xie M, Zhang Q, McMichael JF, Wyczalkowski MA, Leiserson MD, Miller CA, Welch JS, Walter MJ, Wendl MC, Ley TJ, Wilson RK, Raphael BJ, Ding L: Mutational landscape and significance across 12 major cancer types. Nature 2013, 502:333-339.

77. Walter MJ, Shen D, Ding L, Shao J, Koboldt DC, Chen K, Larson DE, McLellan MD, Dooling D, Abbott R, Abbott R, Fulton R, Magrini V, Schmidt H, KalickiVeizer J, O'Laughlin M, Fan X, Grillot M, Witowski S, Heath S, Frater JL, Eades W, Tomasson M, Westervelt P, DiPersio JF, Link DC, Mardis ER, Ley TJ, Wilson RK, Graubert TA: Clonal architecture of secondary acute myeloid leukemia. N Engl J Med 2012, 366:1090-1098.

78. Barrett RD, Schluter D: Adaptation from standing genetic variation. Trends Ecol Evol 2008, 23:38-44.

79. Sequist LV, Waltman BA, Dias-Santagata D, Digumarthy $S$, Turke AB, Fidias $P$, Bergethon K, Shaw AT, Gettinger S, Cosper AK, Akhavanfard S, Heist RS, Temel J, Christensen JG, Wain JC, Lynch TJ, Vernovsky K, Mark EJ, Lanuti M, lafrate AJ, Mino-Kenudson M, Engelman JA: Genotypic and histological evolution of lung cancers acquiring resistance to EGFR inhibitors. Sci Transl Med 2011, 3:75ra26.

80. Chmielecki J, Foo J, Oxnard GR, Hutchinson K, Ohashi K, Somwar R, Wang L, Amato KR, Arcila M, Sos ML, Socci ND, Viale A, de Stanchina E, Ginsberg MS, Thomas RK, Kris MG, Inoue A, Ladanyi M, Miller VA, Michor F, Pao W: Optimization of dosing for EGFR-mutant non-small cell lung cancer with evolutionary cancer modeling. Sci Transl Med 2011, 3:90ra59.

81. Godin-Heymann N, Bryant I, Rivera MN, Ulkus L, Bell DW, Riese DJ 2nd, Settleman J, Haber DA: Oncogenic activity of epidermal growth factor receptor kinase mutant alleles is enhanced by the T790M drug resistance mutation. Cancer Res 2007, 67:7319-7326.

82. Vikis $H$, Sato $M$, James $M$, Wang D, Wang $Y$, Wang M, Jia D, Liu Y, BaileyWilson JE, Amos Cl, Pinney SM, Petersen GM, de Andrade M, Yang P, Wiest JS, Fain PR, Schwartz AG, Gazdar A, Gaba C, Rothschild H, Mandal D, Kupert E, Seminara D, Viswanathan A, Govindan R, Minna J, Anderson MW, You M: EGFR-T790M is a rare lung cancer susceptibility allele with enhanced kinase activity. Cancer Res 2007, 67:4665-4670.

83. Yun $\mathrm{CH}$, Mengwasser KE, Toms AV, Woo MS, Greulich H, Wong KK, Meyerson M, Eck MJ: The T790M mutation in EGFR kinase causes drug resistance by increasing the affinity for ATP. Proc Natl Acad Sci U S A 2008, 105:2070-2075. 
84. Gatenby RA, Silva AS, Gillies RJ, Frieden BR: Adaptive therapy. Cancer Res 2009, 69:4894-4903.

85. Silva AS, Kam Y, Khin ZP, Minton SE, Gillies RJ, Gatenby RA: Evolutionary approaches to prolong progression-free survival in breast cancer. Cancer Res 2012, 72:6362-6370.

86. Taylor TB, Johnson L, Jackson RW, Brockhurst MA, Dash PR: First steps in experimental cancer evolution. Evol Appl 2013, 6:535-548.

87. Yap T, Gerlinger M, Futreal A, Pustzai L, Swanton C: Intratumour heterogeneity: seeing the wood for the trees. Sci Transl Med 2012, 4:127. ps 10.

88. Murtaza M, Dawson SJ, Tsui DW, Gale D, Forshew T, Piskorz AM, Parkinson C, Chin SF, Kingsbury Z, Wong AS, Marass F, Humphray S, Hadfield J, Bentley $D$, Chin TM, Brenton JD, Caldas C, Rosenfeld N: Non-invasive analysis of acquired resistance to cancer therapy by sequencing of plasma DNA. Nature 2013, 497:108-112.

doi:10.1186/gm505

Cite this article as: de Bruin et al.: Intra-tumor heterogeneity: lessons from microbial evolution and clinical implications. Genome Medicine 2013 5:101. 